\title{
Medical Education in Bangladesh
}

MHK Talukder

It is often said "Teachers are not born, they are made". Teaching itself is both an art and a science. "I can not be a good teacher simply because of my father was a good teacher." "I may not be a good teacher because of I was a good student in my life." A medical degree does not necessary give one the ability to be a good teacher. So to develop competent good, ideal, committed, devoted teachers special initiatives to be taken. With these mandates a national institute named Centre for Medical Education (CME) was established in 1983 to develop health manpower in medical education/health professions education. The Centre conducts regular courses, workshops in pedagogy and also has introduced Masters in Medical Education (MMEd) since 2004. However, there is a serious lack of systematic approach to staff development both at the institutional and national level. ${ }^{1}$

At present there are now 23 government medical colleges including Armed Forces Medical College (AFMC). The combined annual intake of government medical colleges is about 2911 students per year. There are about 53 non-government medical colleges. The total annual intake of non-government medical colleges is 4245 students. The total number of govt. dental college is 1 and 8 dental units which per year admit 565 students and non govt. dental colleges are 14 in which combined annual intake is 870 . There are total 81 institutes of health technology (IHT) of which 07 govt. and 74 non govt. with the annual intake of 2041 and 7662 students, respectively. There are total 96 Medical Assistants' Training School (MATS) of which 8 govt. and 88 non govt. which per year admit 700 and 5650 students, respectively. ${ }^{2}$ There are total 82 diploma in nursing institutes of which 43 govt. and 39 non govt. which per year admit 1550 and 1520 students respectively and total annual intake is 3070. Total number of government diploma in midwifery nursing institutes is 20 with the annual intake of 550 students. There are total 19 colleges for basic BSc nursing course of which 07 govt. and 12 non govt. which per year admit 700 and 365 students respectively and total annual intake is 1065 . There are total 14 nursing colleges which conduct post basic BSc nursing course of which 03 govt., 9 non govt. and 2 autonomous which per year admit 375, 270 and 75 students respectively and total annual intake is 7203 .

There are 33 post-graduate institutes of which 23 govt. and 10 non govt. which per year admit 1974 and 169 students respectively and total annual intake is 2143 per year. $^{4}$

1. Md. Humayun Kabir Talukder

Associate Professor (Curriculum Development \& Evaluation) \& Course Director Centre for Medical Education (CME), Mohakhali, Dhaka.
The challenges faced by medical education in Bangladesh, pedagogical, structural and policy related and these are rather typical of many developing and emerging economies around the world. 5 To overcome those challenges the following issues should be addressed properly for the improvement and momentum of medical education in Bangladesh ---

* Career plan for doctors in health sectors should be in four ways since beginning. Those are teaching (teacher), clinical services (consultant), administrative (administrator) and public health services (Public health specialist)

* Accreditation process and quality assurance scheme for all both non government and government medical, dental colleges should be established, strengthened and empowered.

* Provision of autonomy to all the government medical institutes.

* Recruitment and promotion of doctors through PSC/DPC/SSB should be for specific medical institutes maintaining the seniority with all other criteria. Expertise on the subject, merits, performance, sincerity, honesty, discipline, commitment, devotion and loyalty should be considered.

* In addition to financial and administrative audit provision of educational and performance audit to be started for transparency and accountability.

* Provision of licensing examination for newly graduate doctors and provision of Continuing Medical Education (CME) for Continuing Professional Development (CPD) for renewal of registration to be started.

* Provision of institutional practices to be established on the basis of cost sharing principles with provision of non-practicing allowances for all basic and clinical subjects specialties.

* Staff development for all teachers on educational methods such as teaching and learning, instructional materials development, curriculum development, assessment and evaluation should be regularly ensured.

* Establishing a medical education unit (MEU), medical skills centre (MSC) and department of medical education at each institutes with professor, associate professor, assistant professor and lecturer posts for medical educationists. They will be responsible for efficient utilization of MEU and MSC and will arrange appropriate training regularly for the teachers of the institutes.

* List of competencies to be identified for the graduate doctors and to develop competency based curriculum for competent service. Wide range of competencies to be identified for each super specialist and sub specialist. 
* Greater incorporation of information technology (IT) as an enabler of more efficient delivery of education to ensure Evidence Based Medical Education (EBME) and also to develop DIGITAL BANGLADESH in future.

\section{References}

1. Amin, Z, Merrylees, N, Hanif, A \& Talukder, MHK 2008, 'Medical Education in Bangladesh', Medical Teacher, vol. 30, pp. 243-247.

2. Medical Education, Directorate General of Health Services (DGHS), September 2012.

3. Bangladesh Nursing Council(BNC). September 2012.
4. Report on Postgraduate Medical Education in Bangladesh, Directorate General of Health Services (DGHS) and Ministry of Health and family Welfare (MOH\&FW), 2007.

5. Majumder, M. A. A., D'Souza, U. And Rahman, S. (2004) Trends in Medical Education: Challenges and Directions for Need-based Reforms of Medical Training in Southeast Asia. Indian Journal of Medical Sciences, 58 369-380. 